\title{
Cyclic GMP to nicked DNA
}

\section{This month's New on the Market selection includes a new cyclic GMP assay and a DNA nick- translation kit.}

- An economically priced simple and convenient kit to nick-translate DNA in one hour has been introduced by CooperBiomedical. With this kit it is easy to obtain DNA labelled at $2 \times 10^{8}$ d.p.m. per microgram, making preparation of hybridization probes easy and inexpensive. Circle No. 100 on Reader Service Card. - Sepragel, new from Biotechnology Development Corporation, is a range of pre-cast polyacrylamide electrophoresis gel gradients in the popular $16 \times 12 \mathrm{~cm}$ gel sizes. These thin 1.5-mm gels give a high resolving power and good reproducibility for autoradiography and Western blot techniques. Gels are supplied in two buffer systems (SDS and non-SDS) and four gradient ranges $(3-27 \% ; 10-20 \% ; 3-12 \%$; and $17-27 \%)$. For rapid evaluation inexpensive introductory kits are available containing a 16-page instruction manual. Circle No. 101 on Reader Service Card.

- Romicon, Inc. has developed a new membrane for the processing of high purity water (HPW) in the pharmaceutical industry. It is more economical than distillation and more reliable than reverse osmosis. Romicon's HPW membranes can withstand repeated cleaning with strong acids and strong bases, and can remove particulates, bacteria and other debris from water.

Circle No. 102 on Reader Service Card.

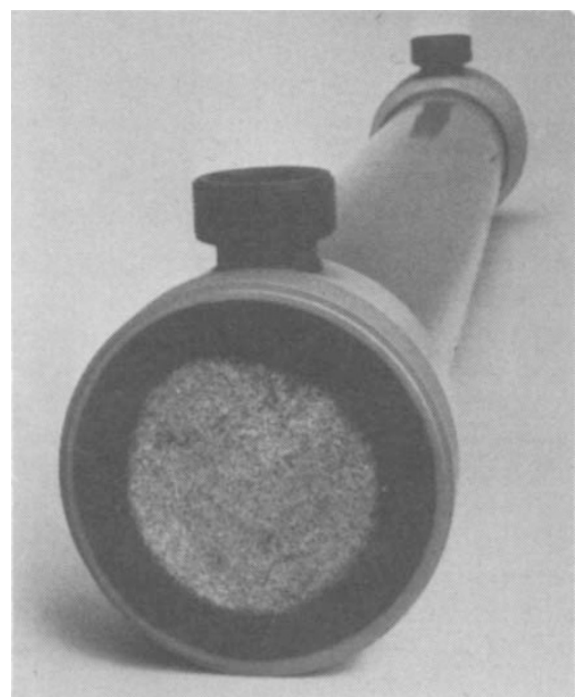

High purity water can be made using Romicon's new filter.

These notes are based on information provided by the manufacturers. For further details circle the appropriate numbers on the Reader Service Card bound inside the journal.
- The Eldex Chromat-a-trol is a microprocessor-based gradient and systems programmer that achieves precise control without the restrictions imposed by many dedicated systems. The Chromat-a-trol will generate binary gradients with most HPLC pumps, as well as control up to 24 external events. The large memory, and capacity to stack and cycle methods, make the Chromat-a-trol a versatile systems controller.

Circle No. 103 on Reader Service Card.

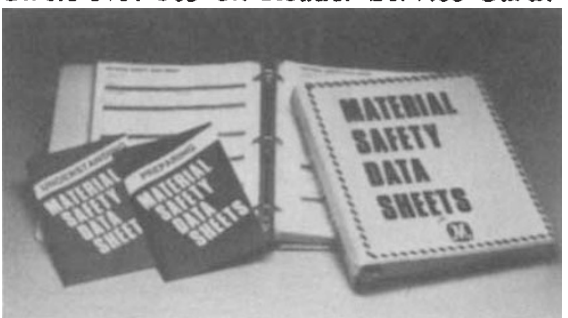

Hazard warnings from Lab Safety Supply.

- The recently introduced OSHA "Hazard Communication Standard and Right to Know" laws make it mandatory that, in the United States, a material safety data sheet be available for each hazardous substance in the workplace. Lab Safety Supply has developed a new ring binder to keep hazard information readily available and protected. The highly-visible binder is equipped with a set of index tabs, 50 sheet protectors, 50 material safety data sheet forms and a booklet on preparing and understanding the data sheets. Binders can also be customized with a company logo. Circle No. 104 on Reader Service Card.

- A new line of threaded ultracentrifuge tubes and caps is available from Sarstedt, Inc. Available in six sizes, these thick-wall reusable polycarbonate or cellulose tubes feature moulded, precision threads and straight, constant internal diameter walls for easy removal of pellets. One-piece caps are anodized aluminium with sealing $\mathrm{O}$ rings and a threaded hole to accommodate rotor cap tools for easy removal. Tubes can be spun at 40,000 to 50,000 r.p.m. depending on tube size and can be used in most Beckman, Kontron and Sorvall fixedangle ultracentrifuge rotors.

Circle No. 105 on Reader Service Card. - Mitsubishi's KF-05 microprocessorcontrolled moisture meter displays and prints out moisture levels in gases, liquids, and solids over a range of $0.01 \%$ (100 p.p.m.) to $100 \%$. Using the Karl Fischer titration method, it automatically titrates to a fixed end point (selectable from 5 to $120 \mathrm{~s})$, and calculates concentration according to one of 10 stored formulas. Circle No. 106 on Reader Service Card.
- The Spectroflow 783 absorbance detector, manufactured by Kratos Analytical, combines high sensitivity, minimal drift and maximum versatility in a compact package that is not only programmable but is also computer-compatible. Flowcells are self-aligning and can be easily changed to allow successful operation in microbore LC, conventional HPLC, fast LC, semiprep LC, open column LC and low pressure LC.

Circle No. 107 on Reader Service Card.

- Biomedical Technologies, Inc. has developed a sensitive cyclic GMP radioimmunoassay kit. Levels of cyclic GMP can be accurately measured from urine, plasma, tissue, cell culture and other sources. The sensitivity of the assay is 1.10 picomoles per tube and 0.005 picomoles per tube for acetylated sample. The kit makes use of a highly specific preconjugated cyclic GMP antibody and an iodine-125 labelled tracer. The protocol includes only three pipetting steps and one incubation, and generates a visible precipitate.

Circle No. 108 on Reader Service Card.

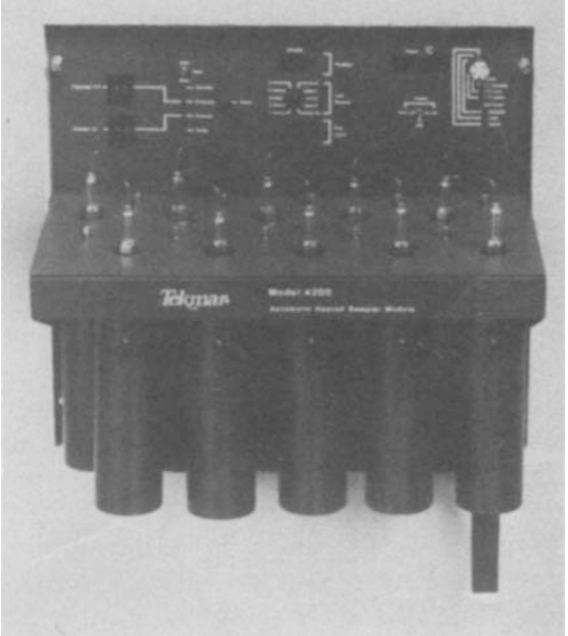

The Tekmar autosampler.

- The Tekmar 4200 is a fully automatic ten position autosampler system with individually heated samples designed for use with the Model 4000 Dynamic headspace concentrator. The Model $\mathbf{4 0 0 0}$ is a fully automatic purge and trap system that allows for the concentration and desorption of volatile organics for GC analysis. Interfaced with the Model 4000 concentrator, the $\mathbf{4 2 0 0}$ permits automatic analysis of as many as ten samples with a sample temperature range of ambient to $173^{\circ} \mathrm{C}$. Circle No. 109 on Reader Service Card. 